\title{
Association of tuberculosis and leprosy in South Africa
}

\author{
E M S GATNER, ${ }^{*}$ E GLATTHAAR, ${ }^{\dagger}$ F M J H IMKAMP \\ \& S H KOK $\ddagger$ \\ *Tuberculosis Research Institute of the South African Medical \\ Research Council, Private Bag X385, Pretoria, 0001 South Africa; \\ †Department of Health, Private Bag X88, Pretoria, 0001 South \\ Africa; and $\ddagger$ Westfort Institution, Private Bag X559, Pretoria, \\ 0001 South Africa
}

Received for publication 7 August 1979

\begin{abstract}
Summary In a study of the simultaneous occurence of pulmonary tuberculosis and leprosy it was found that $13.4 \%$ of leprosy patients were also suffering from tuberculosis on admission to hospital. This figure is considered to accurately reflect the prevalence of the association of these two diseases in South Africa. Tuberculosis occurred throughout the leprosy spectrum and in general responded well when appropriate therapy was added to standard leprosy treatment. There is potential danger in that rifampicin resistant strains of $M$. tuberculosis may be selected for if the clinician fails to recognize the simultaneous condition.
\end{abstract}

\section{Introduction}

Although many publications refer to the association of leprosy and tuberculosis in a patient as being 'not uncommon', few present results which throw any light on the prevalence of such an association, prior to post mortem. Gajwani et al. (1968), ${ }^{1}$ Gupta and Prasad (1971), ${ }^{2}$ Agnihotri et al. (1973), ${ }^{3}$ Premanath and Ramu (1976) ${ }^{4}$ and Bhargava and Mathur $(1976)^{5}$ have reported on clinical and therapeutic details in cases of the simultaneous occurrence of tuberculosis and leprosy. Post mortem examination has variously revealed that in 54.7\% (Mitsuda and Ogawa, 1937), ${ }^{6}$ 27\% (Desikan and Job, 1968) ${ }^{7}$ and 6\% (Sungei Buloh Sanatorium, 1974) ${ }^{8}$ of cases of leprosy death was due to tuberculosis. It is to be expected that the prevalence of the association will vary with individual susceptibility to both diseases and the prevalence of infectious cases of tuberculosis and leprosy in a given population. It is important to be aware of and to recognize such cases in order that they be properly handled. 


\section{Material and Methods}

The study group consisted of 112 consecutive admissions to the Westfort leprosy hospital, Pretoria, and these were classified for leprosy according to the system of Ridley and Jopling (1966). ${ }^{9}$

Each patient had a posterior-anterior chest X-ray performed and the films were read by an experienced tuberculosis doctor who classified them into four groups: (1) no tuberculosis pathology, (2) evidence of current pulmonary tuberculosis, (3) shadows characteristic of an old healed tuberculosis and (4) shadows of uncertain aetiology.

Three early morning sputum specimens were taken from each patient on admission. If a patient was incapable of a productive cough then the three specimens were induced by the inhalation of saline aerosol (Gatner et al. 1977). ${ }^{10}$ The definitive and more sensitive sputum culture technique was preferred to smear microscopy. for making the diagnosis of tuberculosis. Sputa were decontaminated/digested by the $\mathrm{N}$-acetyl-L-cysteine/ $\mathrm{NaOH}$ method (Kubica $e t$ al., $1964)^{11}$ and three tubes of Löwenstein-Jensen culture medium were inoculated per specimen. On aerobic incubation at $35-37^{\circ} \mathrm{C}$ colonies of Mycobacterium tuberculosis generally appeared in three weeks and identity was confirmed by examination of a Ziehl-Neelsen stained smear and positive reactions in the niacin and nitrate reduction tests.

When a diagnosis of tuberculosis in addition to leprosy was made, whether on the basis of radiology or sputum culture, standard leprosy chemotherapy was supplemented with tuberculosis treatment. Rifampicin intake at $450 \mathrm{mg} / \mathrm{day}$ was extended beyond the standard rifampicin course for leprosy and isoniazid (400 mg daily), pyrazinamide ( $2 \mathrm{~g}$ daily) and streptomycin ( $1 \mathrm{~g}$ three times per week) added.

\section{Results}

Table 1 summarizes the results of screening 112 confirmed leprosy cases for pulmonary tuberculosis at the time of admission to hospital. A total of 87 were negative for tuberculosis on radiological and bacteriological examination and 8 persons $(7.1 \%)$ showed radiological evidence of old healed tuberculosis lesions. Five individuals $(4.5 \%)$ were positive for tuberculosis on the basis of both radiological and bacteriological examinations, $7(6.3 \%)$ were diagnosed as having radiologically active pulmonary tuberculosis and $3(2.7 \%)$ were sputum culture positive for $M$. tuberculosis with no radiological evidence of tuberculosis, a not uncommon finding in the field of tuberculosis (Schmidek and Hardy, 1967;12 Husen et al., 1971). ${ }^{13}$ The overall positivity rates for radiology and sputum culture were $10.8 \%$ and $7.2 \%$ respectively. A diagnosis of pulmonary tuberculosis on the basis of radiological and/or bacteriological findings was made in $13.4 \%$ of the patients examined. 
Table 1. Summary of the results of screening 112 confirmed leprosy cases for pulmonary tuberculosis

\begin{tabular}{lc}
\hline Number negative for TB on X-ray and culture & $87(77.6 \%)$ \\
Number with X-ray evidence of old TB & $8(7.1 \%)$ \\
Number positive for TB on sputum culture only & $3(2.7 \%)$ \\
Number positive for TB on X-ray only & $7(6.3 \%)$ \\
Number positive for TB on X-ray and sputum culture & $5(4.5 \%)$ \\
Number with X-ray lesions of uncertain aetiology & $2(1.8 \%)$ \\
\hline
\end{tabular}

A correlation of the diagnostic criteria for tuberculosis with the patients' leprosy classification is shown in Table 2. In this context, the actual status of the 'old TB' group with respect to simultaneous disease is uncertain because of the difficulty of determining the time of onset of leprosy disease. However, tuberculosis appears to occur throughout the spectrum of leprosy. No allusion can be made to the TT classification other than that it is rarely encountered in South Africa and made no appearance in this study.

Table 2. Correlation of TB diagnosis with leprosy classification for 23 patients $\dagger$

\begin{tabular}{lcccc}
\hline & \multicolumn{4}{c}{ Tuberculosis diagnosis } \\
\cline { 2 - 5 } $\begin{array}{c}\text { Leprosy } \\
\text { classification }\end{array}$ & $\begin{array}{c}\text { Culture } \\
\text { positive } \\
\text { only }\end{array}$ & $\begin{array}{c}\text { X-ray } \\
\text { positive } \\
\text { only }\end{array}$ & $\begin{array}{c}\text { Culture } \\
\text { positive } \\
\text { and X-ray } \\
\text { positive }\end{array}$ & $\begin{array}{c}\text { Old } \\
\text { healed } \\
\text { TB }\end{array}$ \\
\hline LL & 2 & 1 & 1 & 2 \\
BL & - & 1 & 2 & 1 \\
BB & - & 1 & - & 3 \\
BT & 1 & 4 & 2 & 1 \\
Burnt out & - & - & - & 1 \\
\hline
\end{tabular}

$\dagger$ The simultaneous disease appellation for the 'old TB' group is uncertain.

Table 3 shows a tabulation of bacteriological and radiological details for 15 leprosy patients who had simultaneous tuberculosis. All cases were placed on a full TB treatment. Of the 8 culture positive individuals, 5 were positive on all three sputum specimens, 2 were positive on two sputum specimens and patient L's sputum was positive at the 3-colony level on only one occasion. Radiologically 7 cases can be described as mild and 5 as severe pulmonary tuberculosis. In 3 cases there was no radiological abnormality detected.

Follow-up of the 15 individuals with diagnosed simultaneous disease revealed that after three months of tuberculosis chemotherapy 10 showed clinical improvement and 5 had either been discharged or there was no follow-up data available. Radiologically, 6 cases showed improvement, 2 were unchanged and 2 were normal throughout. 
Table 3. Bacteriological and radiological details for 15 leprosy patients with simultaneous tuberculosis

\begin{tabular}{|c|c|c|c|}
\hline Patient & $\begin{array}{l}\text { No. of specimens } \\
\text { positive on } \\
\text { sputum culture }\end{array}$ & $\begin{array}{l}\text { Degree of culture } \\
\text { positivity }\end{array}$ & X-ray pathology \\
\hline A & 0 & - & $\begin{array}{l}\text { Early infiltration left } \\
\text { upper lobe }\end{array}$ \\
\hline B & 3 & $100-200$ colonies & Bilateral infiltration \\
\hline $\mathrm{C}$ & 0 & - & Opacities, right apex \\
\hline D & 0 & - & $\begin{array}{l}\text { Nodulations, both lung } \\
\text { fields }\end{array}$ \\
\hline $\mathrm{E}$ & 2 & $21-99$ colonies & No abnormality detected \\
\hline $\mathrm{F}$ & 0 & - & $\begin{array}{l}\text { Fibrotic infiltration left } \\
\text { upper lobe and right apex }\end{array}$ \\
\hline G & 3 & Confluent growth & $\begin{array}{l}\text { Extensive fibrosis whole } \\
\text { left lung and cavities left } \\
\text { apex }\end{array}$ \\
\hline $\mathrm{H}$ & 2 & 21-99 colonies & No abnormality detected \\
\hline I & 3 & $\begin{array}{l}\text { Approximately } \\
500 \text { colonies }\end{array}$ & Light fibrosis, right apex \\
\hline $\mathbf{J}$ & 0 & - & $\begin{array}{l}\text { Fibrotic infiltration right } \\
\text { mid lobe and base }\end{array}$ \\
\hline $\mathrm{K}$ & 0 & - & $\begin{array}{l}\text { Early infiltrate both } \\
\text { apices }\end{array}$ \\
\hline L & 1 & 3 colonies & $\begin{array}{l}\text { Fibrotic infiltrate, right } \\
\text { apex }\end{array}$ \\
\hline M & 3 & Confluent growth & $\begin{array}{l}\text { Fibrosis, left apex, } \\
\text { cavities }\end{array}$ \\
\hline $\mathbf{N}$ & 3 & $21-99$ colonies & No abnormality detected \\
\hline $\mathrm{O}$ & 0 & - & $\begin{array}{l}\text { Fibrotic infiltrate, right } \\
\text { apex }\end{array}$ \\
\hline
\end{tabular}

\section{Discussion}

Leprosy is a non-priority disease in South Africa since there is an annual incidence of only 1 case per 100,000, many occurring amongst citizens of the black states and homelands. The Westfort leprosarium in Pretoria acts as a central diagnostic centre to which all suspected cases in South Africa and the surrounding states are referred. In the course of the present study, all confirmed leprosy cases within a ten-month period were examined for pulmonary tuberculosis on admission. The association is not infrequent when patients with leprosy are examined but is not detected when patients with TB are examined. The overall simultaneous disease rate of $13.4 \%$ is considered to represent an accurate estimate of the prevalence of such a phenomenon in South Africa and whilst causing concern, its recognition enables this problem to be solved. Cases of leprosy where death was due to tuberculosis are rarely encountered.

The rates for radiologically and bacteriologigally diagnosed tuberculosis amongst leprosy patients, $10.8 \%$ and $7.2 \%$ respectively, are relatively high even 
when compared with local figures in this high prevalence tuberculosis area. In random sample tuberculosis prevalence surveys, the Tuberculosis Research Institute has determined culture positivity rates varying between $0.9 \%$ in Lebowa and $4.3 \%$ in the Republic of Transkei (TBRI Annual Report, 1976 and 1977). ${ }^{14}$ The high culture positivity rate for tuberculosis amongst leprosy patients seems likely to be compounded from the high local rates of prevalence of tuberculosis infection and the immunologically compromised leprosy patient. Whilst leprosy is decreasing in South Africa, tuberculosis remains the major infectious disease but the results of the present study do not support Chaussinand's $(1948)^{15}$ belief that tuberculosis is responsible for the decline of leprosy in Europe. The tendency is for the South African black to become infected with $M$. tuberculosis in infancy and youth and most of the cases of pulmonary tuberculosis are considered to result from endogenous reactivation of a previous infection. The suggestion is that leprosy may encourage the concurrent development of tuberculosis.

The standard chemotherapy for leprosy in South Africa is a regimen of dapsone and rifampicin. With the exception of one patient, all leprosy patients who were culture positive for tuberculosis carried a fairly heavy bacterial loading of $M$. tuberculosis. If the clinician handling such cases is unaware of the coincidence of tuberculosis with the leprosy, then a dangerous situation arises wherein a patient may receive monotherapy for tuberculosis with rifampicin. The emergence of rifampicin-resistant strains of $M$. tuberculosis becomes a potential problem which can be avoided by careful screening for tuberculosis and proper management of the simultaneous conditions.

Having completed the exploratory phase of this study the realization comes that there are many facets to this problem. New admissions to hospital have been exclusively considered but long-stay patients, open to infection and disease, have been overlooked. The possibility of the emergence of tuberculosis whilst in hospital must be examined. Immune function parameters in simultaneous disease will also be an area for future examination.

\section{Acknowledgements}

The authors wish to express their gratitude to Dr W S R Studzinski, Medical Superintendent of the Westfort Hospital, for his help and co-operation in the performance of this study and to Mrs $\mathbf{J}$ Koch for assistance with specimen collection.

\section{References}

Gajwami BW, Verma BS, Marwane RK, Pande RS Simultaneous infection with $M$. tuberculosis and M. Leprae. J. Assoc Physicians India, 1968, 16, 563. 
${ }^{2}$ Gupta MC, Prasad M. Associated infection of pulmonary tuberculosis and leprosy. Ind. J. Med. Sci, 1971 25, 183.

3 Agnihotri MS, Rastogi S, Agarwal RC. Tuberculosis and leprosy. Indian J Tuberc, 1973, 20, 136.

4 Premanath M, Ramu G. The association of leprosy and tuberculosis. J Indian Med Assoc, 1976, 67, 143.

5 Bhargava NC, Mathur KC. Simultaneous occurrence of leprosy and pulmonary tuberculosis. Indian J Chest Dis Allied Sci, 1976, 18, 101.

${ }^{6}$ Mitsuda K, Ogawa M. Study of one hundred and fifty autopsies on cases of leprosy. Int $J$ Lepr, 1937, 5, 53.

7 Desikan KV, Job CK. A review of post mortem findings in 37 cases of leprosy. Int. J Lepr, 1968, 36, 32.

8 Sungei Buloh Sanatorium, Malaysia, Annual Report 1974. (Quoted from Premanath and Ramu, 1976).

9 Ridley DS, Jopling WH. Classification of leprosy according to immunity. A five group system. Int J Lepr, 1966, 34, 255.

10 Gatner EMS, Gärtig D, Kleeberg HH. Sputum induction by Saline aerosol. S Afr Med J, 1977, 51, 279

11 Kubica GP, Kaufmann AJ, Dye WE. Comments on the use of the new mucolytic agent, $\mathrm{N}$-acetyl-L-cysteine, as a sputum digestant for the isolation of Mycobacteria. Am Rev Respir Dis, 1964, 89, 284.

12 Schmidek HH, Hardy MA. Pulmonary tuberculosis with normal chest radiographs. Can Med Assoc J, 1967, 97, 178.

13 Husen L, Fulkerson LL, Del Vecchio E, Zack MB, Stein E. Pulmonary tuberculosis with negative findings on chest X-ray films: a study of 40 cases. Chest, 1971, 60, 540.

14 Tuberculosis Research Institute of the South African Medical Research Council. Annual reports, 1976, 1977 and 1978.

15 Chaussinand R. Tuberculose et lèpre, maladies antagoniques. Éviction de la lèpre par la tuberculose. Int J Lepr, 1948, 16, 431. 